ARCHIVO ESPAÑOL DE ARTE, LXXXVIII, 352

OCTUBRE-DICIEMBRE 2015, pp. 403-408

ISSN: 0004-0428, eISSN: 1988-8511

doi: $10.3989 /$ aearte.2015.25

\title{
VARIA
}

\section{NUEVAS NOTICIAS SOBRE HUBERTO ALEMÁN, ESCULTOR AL SERVICIO DE ISABEL LA CATÓLICA}

\author{
Ana Soledad Crespo Guijarro y Francisco Javier Crespo Muñoz \\ Universidad de Granada y Archivo General de Simancas
}

\begin{abstract}
Análisis del contenido de nuevos documentos relativos a la vida y la obra del escultor Huberto Alemán, entallador al servicio de la reina Isabel la Católica, localizados en el Archivo General de Simancas.

Palabras clave: Huberto Alemán; Escultura del siglo XVI; Archivo General de Simancas.

\section{NEW INFORMATION ON HUBERTO ALEMÁN, SCULPTOR IN THE SERVICE OF ISABEL LA CATÓLICA}

The authors analyze the contents of new documents located in the Archivo General de Simancas, relating to the life and work of the sculptor Huberto Alemán, who served queen Isabel la Católica.

Key words: Huberto Alemán; Sculpture; $16^{\text {th }}$ century; Archivo General de Simancas.

El maestro Huberto Alemán o, en su forma más germánica, meister Hubertus, es uno de los escultores más desconocidos de entre los que pusieron su arte al servicio de la reina Isabel la Católica ${ }^{1}$. Diversos estudiosos se han acercado al análisis de los escasos testimonios documentales que hasta la fecha se tenían sobre este entallador de procedencia nórdica (como señalan algunos autores, tal vez de Utrecht), gracias a los cuales se sabía que trabajó para la soberana castellana entre 1500 y 1501 , realizando escultura en piedra (de tamaño natural o más pequeña), talla de madera (siempre con imágenes), diversos relieves en ambos materiales y algunas piezas litúrgicas o dedicadas al culto (todas de madera, aunque en ocasiones bañadas en plata).

Los testimonios documentales más abundantes relativos a meister Hubertus se concentran en el Archivo General de Simancas; los datos simanquinos procedían de la serie de cédulas reales, dentro del fondo Cámara de Castilla, y de los legajos 97 y 106 de la Primera Época de la Contaduría

\footnotetext{
${ }^{1}$ A pesar de que la forma en la que más frecuentemente aparece en la documentación castellana es "Ruberto", el maestro Alemán firmaba como "Hubertus" (Hubach, 2006: 31).
} 
Mayor de Cuentas: en el primero de los casos, se ordenaba el pago al entallador nórdico por la ejecución de diversos encargos escultóricos de temática religiosa; en el segundo, se recogen los asientos del camarero Sancho de Paredes relativos a los pagos, entre otros, a Huberto Alemán, en su caso por la realización de diversos trabajos, entre los que se encuentran ciertas imágenes de la Virgen. Gracias a los datos aportados por esta documentación, se ha podido determinar que el taller del maestro Alemán fue el responsable de la realización de un conjunto variado de obras, desde algunas imágenes de gran tamaño (un Calvario, una Virgen con el Niño, etc.) y un buen número de obras de dimensiones menores (vírgenes y santos particulares), pasando por cinco relieves escultóricos (una Anunciación, una Natividad, el Anuncio de los Pastores, la Epifanía y la Resurrección), hasta ornamentos litúrgicos (custodias, portapaces, etc.). Su destino: fundamentalmente la Catedral de Granada y distintos conventos del otrora solar nazarí.

La mencionada documentación procedente del Archivo General de Simancas comparte naturaleza económica con un testimonio conservado en la National Gallery of Art Library de Washington, del que, como punto a destacar, se ha podido rescatar la firma autógrafa de Huberto Alemán.

Diferente resulta el interesante memorial custodiado en el Archivo Histórico Nacional de Madrid y editado por Felipe Pereda ${ }^{2}$, que contribuye en mayor medida a pergeñar la semblanza de este artista venido del norte de Europa que, a comienzos del siglo XVI, estaba decidido a instalarse en la ciudad de la Alhambra para poner en práctica su nuevo "arte de ymajinería", que había traído a la capital granadina y por el que esperaba recibir de la reina católica "(...) unas casas en la çibdad de Granada e (...) otra cosa más en que me pudiese yo sostener", así como el conveniente pago por el trabajo artístico obra de sus manos. La soberana parece que confió en el buen hacer del artista nórdico (ella costeó los gastos de la imaginería de la que se tiene constancia documental) y en un sistema por el que se podían fabricar imágenes con moldes, técnica introducida por el maestro Huberto desde, muy probablemente, su Utrecht natal y que, ciertamente, constituía una novedad absoluta en la Castilla de la época.

Las precisiones sobre la técnica de fabricación de imágenes, que se desprenden del memorial del maestro Alemán, han sido conjugadas por Felipe Pereda con los estudios realizados sobre las tallas de la Virgen de los Remedios de Villarrasa (Huelva), de la Virgen de la Luz de Lucena del Puerto (Huelva) y de Nuestra Señora del Socorro de Antequera (Málaga) para afirmar que las tres obras salieron, sin lugar a dudas, del taller de meister Hubertus; más difícil le resulta a este autor vincular con el entallador nórdico otras imágenes, hoy desaparecidas, como una Virgen con el Niño, en Prádanos de Bureba (Burgos), y Nuestra Señora de la Luz de Hornillos de Eresma (Valladolid), que por su material y la tecnología con la que fueron fabricadas son producto de un maestro de Utrecht ${ }^{3}$.

Por otro lado, los datos extraídos de la mencionada documentación simanquina han dando lugar a la atribución de ciertas obras al entallador nórdico.

De esta manera, la Virgen de la Puerta de la Justicia de la Alhambra viene siendo atribuida a Huberto Alemán, desde que así lo estableciese, en 1919, Antonio Gallego Burín ${ }^{4}$, basándose en las citadas cédulas reales, editadas por Salvador Sanpere y Miquel en $1902^{5}$; autores posteriores se han reafirmado en la atribución establecida por Gallego Burín, apoyados, además, en la documentación de la Contaduría Mayor de Cuentas ${ }^{6}$. En los últimos años, no obstante, se ha venido contestando la postura existente con respecto a la autoría de esta talla, de suerte que cuestiones relativas a dimensiones, material y estilo rebaten que esta Virgen se deba a Huberto Alemán ${ }^{7}$.

\footnotetext{
2 Pereda, 2007: 382-383.

${ }^{3}$ Pereda, 2007: 321-339.

${ }^{4}$ Gallego, 1919: 28. Dedica un trabajo específico en la década de los cuarenta (Gallego, 1942-1944: 109-113).

${ }^{5}$ Más recientemente, las cédulas han sido editadas por José María Azcárate Ristori (Azcárate, 1982: vol. 2, 219-221).

${ }^{6}$ Domínguez, 1993: 110; 1995: 316. Pereda, 2007: 364-367.

${ }^{7}$ Ortega/Villanueva/Fernández/Martín/Sameño, 1997: 60-61.
}

Arch. esp. arte, LXXXVIII, 352, OCTUBRE-DICIEMBRE 2015, 403-408 ISSN: 0004-0428, eISSN: 1988-8511, doi: 10.3989/aearte.2015.25 
Partiendo de la misma base documental, Felipe Pereda vincula inequívocamente a la Virgen de la Antigua de la Catedral de Granada con el meister Hubertus ${ }^{8}$, algo que ya apuntara, de forma más ambigua, Joaquín Yarza, que le supone afincado en la ciudad de la Alhambra, en un taller improvisado, con varios colaboradores a su servicio ${ }^{9}$. Como en el caso de la Virgen de la Puerta de la Justicia, este tipo de atribuciones no dejan de estar exentas de problemas ${ }^{10}$.

Así las cosas, recientemente, gracias al impulso en el tratamiento y difusión archivística que viene realizando la Subdirección General de los Archivos Estatales con los fondos gestionados por este organismo, ha sido posible el hallazgo de cuatro nuevos documentos, datados en $1500^{11}$, conservados en el fondo Registro General del Sello del Archivo General de Simancas y relativos a la vida y obra del maestro Huberto Alemán, los cuales completan significativamente la información sobre este escultor que sirvió a la reina Isabel la Católica.

La documentación recientemente localizada gira en torno al litigio que el maestro Alemán mantuvo con un personaje tan importante para el panorama sociopolítico de la Andalucía del siglo XVI como Francisco Enríquez de Ribera, quinto adelantado mayor de Andalucía, segundo conde de Los Molares y señor de Alcalá de los Gazules, Bornos y Espera, fallecido en 1509. La pendencia arranca seis años antes de la fecha de los documentos, en 1494, momento en el que, según la documentación, Huberto Alemán ya se encontraba en territorio castellano. Por motivos poco claros, viaja a Alcalá de los Gazules para entrevistarse con el adelantado, el cual aprovecha para retenerlo en contra de su voluntad desde el 15 de agosto hasta el 25 de diciembre del mencionado año. Pasada la festividad navideña, meister Hubertus es trasladado a la villa de Bornos, "en vna azémila, con vna cadena e vnos grillos a los pies"; allí es obligado a trabajar, junto con cuatro oficiales, en la ornamentación de "vnas casas que tenía començadas" Francisco Enríquez de Ribera en esta localidad gaditana ("labró las dichas casas e hiso en ellas ocho mil florones de talla a su costa e misión”), lo cual le ocupó hasta el Viernes Santo de 1495. Terminada la obra, Huberto Alemán recobra la libertad pero marcha de Bornos sin cobrar un solo maravedí ${ }^{12}$.

Van a pasar seis años hasta que el maestro Alemán decida dirigirse a la Corona para reclamar al adelantado de Andalucía el dinero que le adeuda por su trabajo; no hay constancia de que la causa se dirimiese antes en otras instancias de Justicia. Es posible que meister Hubertus se sintiese protegido en esos momentos por la reina Isabel la Católica, para la que, por aquel entonces, ya estaría trabajando, y se decidiese a enfrentarse con tan conspicuo noble. En todo caso, el temor por la reacción de Francisco Enríquez de Ribera ante su denuncia le debía atenazar, de ahí el amparo real que solicita y obtiene ${ }^{13}$.

Sin embargo, todo parece indicar que el maestro Huberto Alemán midió mal sus fuerzas. Por lo que transmiten los documentos, el adelantado Ribera decidió contraatacar por la vía legal y reclamó al entallador ciertos maravedís, muy posiblemente vinculados a una carga de trigo que, a instancias del noble andaluz, el maestro Alemán llevó a Flandes (de donde, como ya se ha indicado, con casi total certeza era oriundo); Catalina Galera, mujer del meister Hubertus, trató de conseguir

${ }^{8}$ Pereda, 2007: 364-367.

9 Yarza, 1993: 24; 2002: 231.

${ }^{10}$ Crespo, 2014.

${ }^{11}$ Los primeros documentos recientemente localizados se datan unos meses antes (en abril de 1500) con respecto a la documentación de la que hasta ahora se tenía constancia sobre Huberto Alemán (agosto de ese año), y se extienden hasta septiembre del primer año del siglo XVI, coincidiendo con los documentos tanto del Archivo Histórico Nacional como de la Contaduría Mayor de Cuentas del Archivo General de Simancas.

12 Archivo General de Simancas (a partir de ahora AGS), Registro General del Sello (a partir de ahora RGS), 150004,28

13 AGS, RGS, 150004, 27.

Arch. esp. arte, LXXXVIII, 352, octUBRE-DICIEMBRE 2015, 403-408 ISSN: 0004-0428, eISSN: 1988-8511, doi: 10.3989/aearte.2015.25 
pruebas del feliz desenlace de este negocio, pidiendo, sin éxito, a los escribanos de Bornos la carta de finiquito que el señor de la villa había otorgado a favor de su marido ${ }^{14}$. Por aquel entonces (agosto de 1500), Huberto Alemán probablemente ya estaría en la cárcel pública de Sevilla, encerrado por orden de don Juan de Silva, conde de Cifuentes y asistente de la ciudad, con motivo de la mencionada demanda económica interpuesta por don Francisco Enríquez de Ribera ${ }^{15}$. No obstante, nuevamente se aprecia el favor y protección de los Reyes Católicos hacia el entallador de la soberana castellana: por un lado, el Consejo Real ordena a los escribanos de Bornos la entrega a Huberto Alemán de la carta de finiquito reclamada y, por el otro, este organismo interpela al asistente de Sevilla a que dirima cuanto antes la causa entre el maestro Alemán y el adelantado Ribera.

Se desconoce el desenlace del litigio, pero sí se sabe que meister Hubertus fue liberado poco después de que el Consejo Real se dirigiese a don Juan de Silva (septiembre de 1500), pues las cédulas de la Cámara de Castilla de diciembre de este año establecen los pagos por las obras realizadas directamente a Huberto Alemán, y no a Catalina Galera, como en meses anteriores.

Por lo tanto, a través del análisis de los documentos simanquinos recientemente localizados, es posible extraer los siguientes datos sobre el maestro Huberto Alemán:

1. Se ratifica el hecho de que meister Hubertus muy probablemente fue oriundo de Flandes.

2. Alrededor de 1494 ya se encontraba en territorio castellano, en donde había entablado contacto con la nobleza andaluza, más concretamente con la importante familia de los Ribera. Es difícil saber si, por aquel entonces, Huberto Alemán ya se encontraba afincado en Castilla o si se traslada a Andalucía en esos momentos, por iniciativa propia o quizás llamado por el adelantado Francisco Enríquez de Ribera, con el que mantenía negocios al margen de los puramente artísticos, que tal vez provocaron su encarcelamiento en Alcalá de los Gazules y el tiempo que posteriormente pasó trabajando en Bornos, obligado y de forma gratuita.

3. El entallador nórdico desempeñó su trabajo artístico de forma obligada, al servicio del adelantado de Andalucía: llevó a cabo la ornamentación de la casa que, desde 1490, estaba construyendo Francisco Enríquez de Ribera en la mencionada localidad gaditana. Nada se ha podido conservar de la obra del maestro Alemán, toda vez que, en primer lugar, Fadrique Enríquez de Ribera, hermanastro y sucesor del señor de Bornos, erigió el palacio actual sobre la construcción de este último, y que, en segundo lugar, si algo hubiese sobrevivido a esta inicial intervención, ha perecido fruto del abandono y de las diversas remodelaciones arquitectónicas y funcionales del edificio.

AleFrabajando desde, al menos, 1500, para la reina Isabel la Católica, de la que Huberto los mán se sentía amparado, ésta no dudó en proteger y salir en ayuda de su escultor ante problemas acaecidos con el adelantado de Andalucía.

5. Estante en la capital hispalense en septiembre del mencionado año (en uno de los documentos de abril de 1500 se le considera "veçino de la çibdad de Seuylla"), seguramente meister Hubertus abandonó a continuación esta ciudad rumbo a Granada, no sólo en busca de nuevas oportunidades laborales sino también huyendo de la embarazosa situación que se había creado con la familia Ribera.

La documentación datada con posterioridad a los acontecimientos relatados en los párrafos precedentes es ya bien conocida. A partir de 1501 se pierde por completo la pista de Huberto Alemán; no sería descabellado pensar que alrededor de ese año se produjo el deceso del maestro entallador, toda vez que, por un lado, no se han hallado testimonios del escultor de

\footnotetext{
${ }^{14}$ AGS, RGS, 150008, 161.

15 AGS, RGS, 150009, 37.
} 
origen flamenco realizando nuevos trabajos para la reina Isabel la Católica (que no parecía insatisfecha con su obra), sino que tampoco, por otro lado, se han encontrado documentos referentes a su persona con posterioridad a esa fecha (por ejemplo, en el Archivo de Protocolos Notariales de Granada). En cualquier caso, no se puede descartar que los archivos, guardianes de la Historia, den nuevas sorpresas relativas al meister Hubertus.

\section{APÉNDICE DOCUMENTAL}

1500, abril, 5. Sevilla.

Comisión al licenciado Gallego, alcalde de Casa y Corte, para que entienda en la demanda presentada por Huberto Alemán, entallador, vecino de Sevilla, sobre los agravios recibidos de Francisco Enríquez de Ribera, adelantado de Andalucía.

AGS, RGS, 150004,28

[Arriba izquierda:] Ruverto Alemán.

[Arriba centro:] Cruz. Comisión.

Don Fernando e doña Ysabel etcétera. A vos, el liçençiado Gallego, alcalde de la nuestra Casa e Corte e nuestro jues de resydençia de la çibdad de Seuylla. Salud e graçia. Sepades que Ruberto Alemán, entallador, estante en esa dicha çibdad, nos hiso relaçión etcétera diziendo que puede aver seys años, poco más o menos, que, estando don Françisco Henríques de Ribera, adelantado del Andalusýa, en la villa de Alcalá de los Gazules, dis que vyno el dicho Ruberto Alemán a le desyr çiertas cosas que le ayýa mandado que sopiese e des (sic) que le tovo en la dicha villa dis que por fuerça e contra su voluntad, le mandó prender e le echó en muy grandes prisiones, e dis que le tovo preso desde el día de Santa María de agosto fasta el día de Navidad syn le oyr ni mostrar por qué le tenía preso, e que, pasado el dicho día de Navidad, dis que le mandó sacar de la dicha presyón e llevar en vna azémila con vna cadena e vnos grillos a los pies fasta otro logar suyo, que se dise Bornos, en el qual dis que quería labrar vnas casas que tenía començadas, e dis que allí el dicho adelantado le mandó que le diese fianças bastantes e que le tomó juramento que no se avsentaría ni yría del dicho logar syn su liçençia e mandado, e dis que, no contento desto, le hiso echar vnos fierros a los pies como sy fuera //cautyvo e dis que le mandó que tomase consygo los dichos quatro ofiçiales $\mathrm{e}^{16}$ que le labrase las dichas casas del dicho su ofiçio de talla e a su costa del dicho Ruberto Alemán, e dis quél, viéndose apremiado e que no podía haser otra cosa saluo lo quel dicho adelantado le auýa mandado, dis que ${ }^{17}$ que (sic) tomó consigo los dichos quatro ofiçiales e labró las dichas casas e hiso en ellas ocho mil florones de talla a su costa e misión, e dis que costó en tienpo en faser la dicha obra desde pasada la dicha Pascua fasta el Viernes Santo siguiente del dicho año, e dis que, acabada de haser la dicha obra, le mandó soltar para que se fuese syn le pagar cosa alguna de todo lo que en ello auýa gastado, e dis que, a esta cabsa, él ha gastado todo quanto tenía e está perdido, en lo qual dis quél recibió mucho agrauyo e daño, e nos suplicó e pidió por merçed sobre ello le proueyésemos de remedio con justiçia, o como la nuestra merçed fuese, lo qual, visto etcétera e confiando de vos etcétera porque vos mandamos que luego veades lo susodicho e, llamadas e oýdas las partes a quien atañe, symplemente e de plano, syn escriptura ni figura de juysio, saluo solamente la verdad sabida, fagades e administredes çerca de lo susodicho, lo que fuera justiçia por vuestra sentençia o sentençias etcétera, con poder etcétera. Dada en la çibdad de Seuylla, a cinco de abril de mil e quinientos años. Iohannes, episcopus ouetensis. [al margen]: Filipus, doctor. Iohannes, liçençiatus. Martinus, doctor. Liçençiatus Çapata. Ferdinandus Tello, liçençiatus. Ferdinandus Tello, liçençiatus (sic). Yo, Juan Ramíres, escriuano de cámara, etcétera.

\footnotetext{
16 Tachado: la.

17 Tachado: lo.
}

Arch. esp. arte, LXXXVIII, 352, octUBRE-DICIEMBRE 2015, 403-408 ISSN: 0004-0428, eISSN: 1988-8511, doi: 10.3989/aearte.2015.25 


\section{BIBLIOGRAFÍA}

Azcárate Ristori, José María (1982): Colección de documentos para la Historia del Arte en España. Madrid; Zaragoza: Real Academia de Bellas Artes de San Fernando; Museo e Instituto de Humanidades "Camón Aznar".

Domínguez Casas, Rafael (1993): Arte y etiqueta de los Reyes Católicos. Artistas, residencias, jardines y bosques. Madrid: Alpuerto.

Domínguez Casas, Rafael (1995): "Dos artistas nórdicos activos en al corte granadina de la Reina Isabel la Católica: el maestre Ruberto Alemán, entallador, y el joyero Petrequín Picardo”. En: VVAA (1995): Homenaje al profesor Martín González. Valladolid: Universidad, pp. 315-319.

Fernández Bayton, Gloria (1967): “Roberto Alemán, escultor de Isabel la Católica”. En: Archivo Español de Arte, 40 (157), Madrid, p. 83.

Gallego Burín, Antonio (1919): La Alhambra. Granada.

Gallego Burín, Antonio (1942-1944): “Una obra de maestre Ruberto Alemán. La Virgen de la Puerta de la Justicia". En: Cuadernos de Arte de la Universidad de Granada, 7-9, Granada, pp. 109-113.

Hubach, Hanns (2006): “Hubertus Alemán, ‘entallador'. Ein Bildhauer im Dienst Königin Isabellas der Katholischen zur Zeit der Maurenbekehrung in Granada”. En: Das Münster, 59, Ratisbona, pp. 30-37.

Ortega y Ortega, Enrique / Villanueva Romero, Eva / Fernández Ruiz, Eugenio / Martín García, Lourdes / Sameño Puerto, Marta (1997): “Cinco siglos a través de Santa María de la Alhambra. Investigaciones y tratamiento de una escultura del siglo XV”. En: Boletín del Instituto Andaluz del Patrimonio. 21, Sevilla, pp. 59-70.

Pereda, Felipe (2007): Las imágenes de la discordia. Política y poética de la imagen sagrada en la España del 400. Madrid: Marcial Pons.

Yarza Luaces, Joaquín (1993): Los Reyes Católicos. Paisaje artístico de una Monarquía. Madrid: Nerea.

Yarza Luaces, Joaquín (2002): “Isabel la Católica coleccionista, ¿sensibilidad estética o devoción?” En: Valdeón Baruque, Julio (ed.): Arte y cultura en la época de Isabel la Católica. Valladolid: Ámbito, pp. 219-248.

Fecha de recepción: 24-IX-2014

Fecha de aceptación: 04-II-2015

Arch. esp. arte, LXXXVIII, 352, OCTUBRE-DICIEMBRE 2015, 403-408 ISSN: 0004-0428, eISSN: 1988-8511, doi: 10.3989/aearte.2015.25 